\title{
ACUTE MYELOID LEUKEMIA AFTER CHEMOTHERAPY: REPORTING CLINICAL CASE SERIES IN THE DEPARTMENT OF CHEMOTHERAPY - CENTER OF ONCOLOGY - 103 MILITARY HOSPITAL AND RETROSPECTIVE LITERATURE REVIEW
}

\author{
Ho Viet Hoanh*, Nguyen Van Ba*, Tran Van Ha*, Ha Van Tri*
}

\section{ABSTRACT}

Recently, Secondary cancers, particularly acute myeloid leukemia after chemotherapy have been significantly concerned. Our team at the Department of Chemotherapy - Center of Oncology - 103 Military Hospital reports clinical case series diagnosed with acute myeloid leukemia after breast, colon, stomach cancer treatments and retrospective literature review.

\section{INTRODUCTION:}

In cancer treatment, chemotherapy is an effective and widespread-used method. One of the late complications of chemotherapy is acute myeloid leukemia (AML). Although the main causes of this is unclear, it has been confirmed that AML after chemotherapy is correlated with the use of some toxic agents. Previous reports indicated some toxic drugs related to AML include: Alkylating agents (cyclophosphamide, Oxaliplatin...), topoisomerase II inhibitors (Doxorubicin, epirubicin...), anti-metabolic (5-flouruoracil, fludarabine), microtubule inhibitors (Docetaxel, paclitaxel), granulocyte clonal stimulating factors.

In 2018, Morton and his assistants studied data from SEER (Surveillance,

\footnotetext{
* 103 Military Hospital, Military Medical University

Responsible person: Ho Viet Hoanh

Email: hoviethoanh@gmail.com

Date of receipt: 01/6/2021

Date of scientific judgment: 06/7/2021

Reviewed date: 16/7/2021
}

Epidemiology, and End Results Program) in adult cancer patients aged 20 to 80 years. 801 patients with acute myeloid leukemia were detected from 426,086 patients who were previously treated with chemotherapy. In which, the proportion of patients receiving chemotherapy with or without radiation therapy diagnosed with acute myeloid leukemia increased by the time of treatment for primary malignancy, and the proportion of breast cancer patients accounted for approximately $30 \%$ of all the AML patients. This is a very important issue for clinicians to focus on monitoring and detecting, in order to have early intervention and improve the quality of cancer treatments. Recently, in the Department of Chemotherapy - Center of Oncology- 103 Military Hospital, we have encountered 3 cases of acute myeloid leukemia diagnosed after chemotherapy for breast, colon, and stomach cancer. We inform and retrace the literature for our colleagues to refer to.

\section{REPORTING OF CLINICAL CASE SERIES}

1. Case 1: A patient with AML diagnosed after chemotherapy for breast cancer.

A 37-year old female patient, archive number: A71-17-0427, In September 2016, the patient was examined at K3 hospital, diagnosed with right breast cancer, underwent right total mastectomy and axillary lymphadenectomy. Histopathological 
diagnosis: Carcinoma, triple - negative. The patient received adjuvant treatment with $4 \mathrm{AC}$ - 4T regimen. After that, there was a local recurrence, the patient was transferred to 2 cycles of the TAC regimen. In December 2016, the patient was admitted to Oncology centre - 103 military hospital. Clinical examination: Local injury with swelling and necrotic fluid at the right breast site and large right axillary lymph nodes. Patients received palliative radiation at the dose of $30 \mathrm{~Gy}$ and Gemcitabine/ Docetaxel regimen, after 2 cycles, severe neutropenia was observed. At that time, the White blood cell count test did not detect abnormal cells, the red blood cells and platelets were slightly decreased, the liver was not enlarged. The patient was treated with granulocyte clonal stimulating factor + antibiotics. After 1 week, the patient presented with fever, sternum pain, anemia, a total white blood cell count of $18 \mathrm{G} / \mathrm{l}$, mononuclear cells (probable Blast) accounted for 80\%, LDH: 3132 U/l. Bone marrow aspiration was performed. Diagnosis is determined: acute myeloid leukemia type M2. Treated with $3+7$ regimen (Doxorubicin/Cytarabine). Results: Breast damage was reduced, but clinical and laboratory symptoms of acute myeloid leukemia were not reduced. The patient was determined not to respond to treatment for acute leukemia and died after 3 months of diagnosis due to complications of acute myeloid leukemia.

2. Case 2: A patient with AML diagnosed after chemotherapy for colon cancer

A 61-year old man, archive number: A2019-1781. In October 2018 the patient was examined at the department of abdomen surgery, diagnosed with sigmoid colon cancer stage IV with a metastatic lesion in segment VI of the liver. Histopathological diagnosis: adenocarcinoma. Surgery with segmental colonic resection and tumorectomy of metastatic lesions in the liver was performed. 2 months later, the patient was taken PET/CT test. The result indicated multiple metastatic lesions in the liver. The patient was consulted and decided to take 6 cycles of the FOLFIRINOX regimen (Irinotecan, 5FU, Oxaliplatin), (ended in April 2019) because of severe neutropenia, anemia, and thrombocytopenia. At that time patient was painless and physical examination did not detect spleen enlargement, there was not abnormal in white blood cell count test. The patient was treated with granulocyte clonal stimulating factors + antibiotics and blood transfusion. The disease was provisionally stable and the patient was discharged from the hospital. In July 2019, the patient presented with fever, clinical examination: sternum pain, hepatomegaly 3 $\mathrm{cm}$ below the right costal margin, not enlarged spleen, natural subcutaneous hemorrhage was caused by thrombocytopenia. Total white blood cell count of $210 \mathrm{G} / \mathrm{l}, \mathrm{LDH}: 1207 \mathrm{U} / \mathrm{l}$, immature white blood cells in peripheral blood was 68\%. Red blood cells: 2.2 T/1; Platelets: 36 G/l. Bone marrow aspiration was performed. Diagnostic results: Acute myeloid leukemia type M6 (Figure 1). The patient died 3 days after diagnosis due to cerebral hemorrhage.

3. Case 3: A patient with AML diagnosed after chemotherapy for gastric cancer.

A 60-years old male patient, archive number: A20-19-1785. In May 2017, the patient was examined at the department of abdomen surgery, diagnosed with gastric cancer, pancreatic invasion $\mathrm{T} 4$, underwent surgery to remove the entire stomach, and the 
esophagus was then connected to the first part of jejunum (in end-to-end anastomosis). Histopathology result: Poorly differentiated carcinoma. After that, the patient was consulted and decided to receive adjuvant chemotherapy at the central of oncology with an EOF regimen (Epirubicin, oxaliplatin, 5FU). After 2 cycles the disease progressed with lung metastasis, the patient continued chemotherapy for 6 cycles (ended in March 2018), then switched to maintain Cisplatin/capecitabine. During treatment, the patient was taken granulocyte clonal

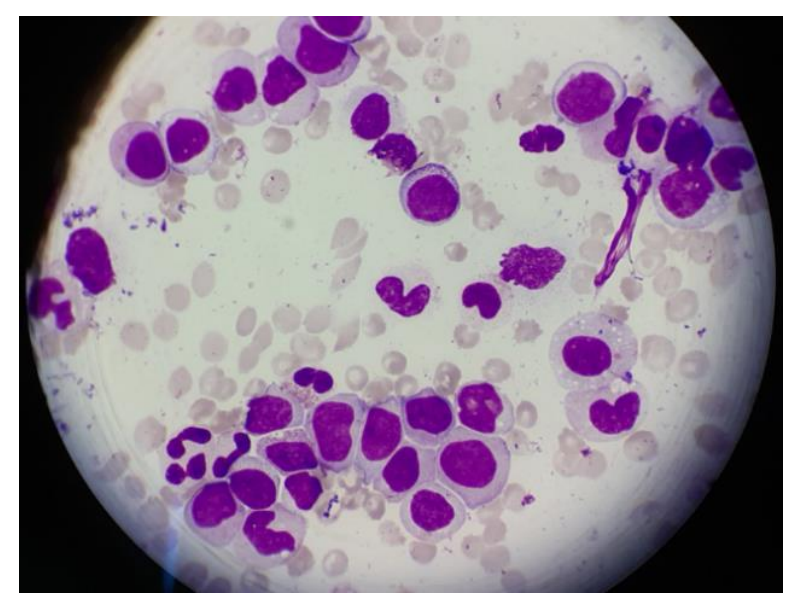

Figure 1. Image of many immature cells in peripheral blood on the slide of clinical case 2. (Wright-Giemsa stain, $\times 100$ )

\section{DISCUSSION}

According to the classification of the World Health Organization (WHO) in 2016, there are two types of therapy-related myelodysplastic syndrome and acute myeloid leukemia (t-MDS/AML) depending on the causative therapeutic exposure: an alkylating agent (Cyclophosphamide) - related type and a topoisomerase II inhibitor (Doxorubicin, epirubicin ...) - related type. Akylating agent stimulating factor. In July 2019, the patient manifested fever. Physical examination: Liver, spleen, lymph nodes were not enlarged, sternum tenderness, natural subcutaneous hemorrhage caused by thrombocytopenia, no mucosal hemorrhage. Total white blood cell count of 94 G/l, immature white blood cells in peripheral blood was 68\%, Red blood cell: $2.65 \mathrm{~T} / \mathrm{l}$; Platelets: 20 G/l, LDH: 996 U/l (Figure 2). Bone marrow test: acute myeloid leukemia. The patient died after diagnosis.

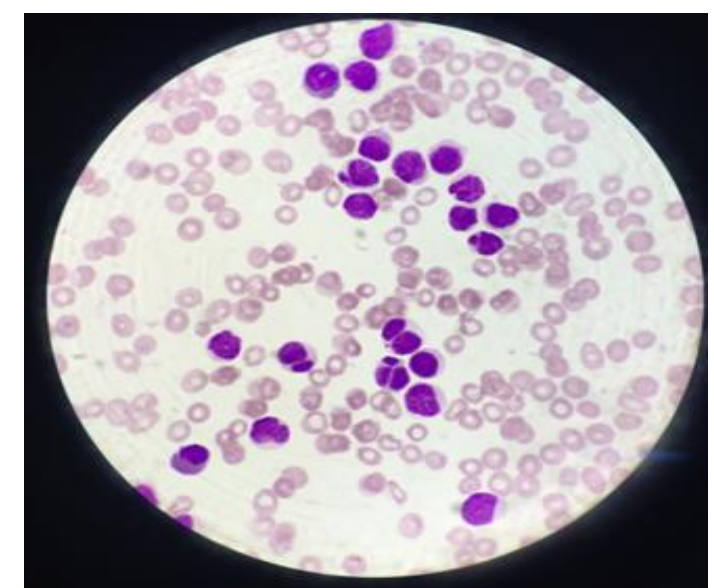

Figure 2. Image of many immature cells in peripheral blood on the slide of clinical case 3. (Wright-Giemsa stain, $\times 100$ )

- related t-MDS/AML usually appears 4 to 7 years after exposure to the mutagenic agent, often has a preceding myelodysplastic phase and a poor prognosis. In contrast to alkylating agent-related t-MDS/AML, AML secondary to topoisomerase II inhibitors often does not have a preceding myelodysplastic phase and has a better prognosis. 
Table 1. Differences between chemotherapy agents and acute myeloid leukemia.

\begin{tabular}{|l|l|l|}
\hline & $\begin{array}{l}\text { Alkylating agents } \\
\text { (Ex: Cyclophosphamid) }\end{array}$ & $\begin{array}{l}\text { Topoisomerase II inhibitors } \\
\text { ( Ex: Doxorubicin, epirubicin) }\end{array}$ \\
\hline Appear & late (median 4- 7 years) & early (median 2 - 3 years) \\
\hline FAB categorized & M1/M2 & M4/M5 \\
\hline $\begin{array}{l}\text { Preceding } \\
\text { myelodysplatic phase }\end{array}$ & $\begin{array}{l}\text { Two-thirds of patients present with } \\
\text { MDS and the remainer with AML } \\
\text { with myelodysplatic features. }\end{array}$ & $\begin{array}{l}\text { Does not have preceding } \\
\text { myelodysplatic phase. }\end{array}$ \\
\hline Abnormalities & Chromosomes 5 and 7 & $\begin{array}{l}\text { Associated with balanced } \\
\text { translocations involving chromosome } \\
\text { bands 11q23 or 21q22 }\end{array}$ \\
\hline Prognosis & Poorer than primary AML & The same as primary AML \\
\hline
\end{tabular}

Breast cancer is a common solid cancer in women. Early detection by mammography screening and early treatment is considered a cure. Treatment methods include surgery, chemotherapy, radiotherapy, hormone therapy, and biological therapy. Chemotherapy is a common method for this cancer. For the patient with early - stage, late complications after treatment are of great concern. In breast cancer patients who underwent chemotherapy with recurrent myelosuppression can cause myelodysplastic syndrome or acute myeloid leukemia. When diagnosed with acute myeloid leukemia, the prognosis is very poor and this rate is reported to be $0.2-0.5 \%$. In one study that monitored a large number of breast cancer patients in Northern Ireland, each year there were 1079 cases diagnosed with breast cancer and 300 patients underwent adjuvant chemotherapy, in which there were about 1 to 2 cases suffered from acute myeloid leukemia after treatment.

In our clinical case of breast cancer, the prognosis of triple-negative breast cancer was very poor. The patient was treated with highly toxic regimen which contained an alkylating agent (cyclophosphamide), a topoisomerase II inhibitor agent (doxorubicin), and a microtubular inhibitor agent (docetaxel). The disease progressed, requiring continuous chemotherapy over a long period of time and the use of granulocyte clonal stimulating factors. All of these were reported as high-risk factors causing therapy-related acute myeloid leukemia. After diagnosing and treating with the regimen for primary acute myeloid leukemia, the disease was unresponsive and the patient died after 3 months of diagnosis.

A baseline study by NCI that analyzed data of 420000 women with breast cancer found that younger patients and patients with lympho nodes involvement were at higher risk of developing acute myeloid leukemia during survival due to exposure to toxic agents used in the treatment plan or potential genetic factors. Some other risk factors include: the dose of chemotherapy, combine chemotherapy and radiotherapy as adjuvant therapy for breast cancer or the use of granulocyte clonal stimulating factors. For breast cancer patients with lymph nodes metastasis treated with Taxan- containing 
regimen and used granulocyte clonal regimens such as XELOX (oxaliplatin + stimulating factors for prophylaxis is the capecitabine), ECF (Epirubicin, cisplatin and current trend to minimize infection 5FU), monotherapy with Doxetaxel or complications. Several studies have also colorectal cancer treated with Folfox regimen shown that supplementation with granulocyte (Oxaliplatin, 5FU) has the potential to cause stimulating factors, monoclonal antibody acute myeloid leukemia. Both of our drugs, and radiation therapy are risk factors gastrointestinal cancers used the 3-agent for acute myeloid leukemia.

For gastrointestinal cancers such as gastric cancer treated adjuvant chemotherapy regimen of EOF and FOLFIRINOX, which are the high-risk regimens for acute myeloid leukemia.

Table 2. Therapy-related acute myeloid leukemia following chemotherapy with oxaliplatin and or capectitabine

\begin{tabular}{|c|c|c|c|c|c|}
\hline Authors & $\begin{array}{c}\text { Age } \\
\text { /gender }\end{array}$ & $\begin{array}{l}\text { Primary } \\
\text { cancer }\end{array}$ & $\begin{array}{l}\text { Chemotherapy } \\
\text { regimen }\end{array}$ & $\begin{array}{l}\text { Therap- } \\
\text { related } \\
\text { leukemia }\end{array}$ & Chromosome test \\
\hline $\begin{array}{l}\text { Carneiro, et } \\
\text { al }\end{array}$ & 56/female & Cecum & FOLFOX-4, FOLFOX-6 & AML & $\begin{array}{l}\text { Deletion of } \\
\text { chromosome } 5,7,20 \\
\text { and } 21, \text { as well as } \\
\text { trisomy } 8 \text { and loss of } \\
\text { chromosome } 3,1\end{array}$ \\
\hline $\begin{array}{l}\text { Damodaran, } \\
\text { et al (2012) }\end{array}$ & $63 /$ male & Esophagus & Capecitabine, OXP & AML & $\begin{array}{l}47, X, \operatorname{der}(Y) t(Y ; 3)(q 12 ; \\
q 21),+8(21)\end{array}$ \\
\hline $\begin{array}{l}\text { Tansley, et } \\
\text { al }\end{array}$ & 66/male & Colon & Capecitabine & AML & Not taken \\
\hline $\begin{array}{l}\text { Sapiro S, et } \\
\text { al (2007) }\end{array}$ & 63/female & Colon & Capecitabine & AML & $\begin{array}{l}\text { Associated to gene } \\
\text { rearrangement of MLL }\end{array}$ \\
\hline $\begin{array}{l}\text { Zübeyde Nur } \\
\text { Özkurt } \\
\text { (2018) }\end{array}$ & 39/female & Breast & Capecitabine & AML & $\begin{array}{l}\text { Associated to gene } \\
\text { rearrangement of } \\
46 X X \\
(10 ; 11)(q 22 ; q 23) ; \\
\text { JAK2 gene mutation }\end{array}$ \\
\hline
\end{tabular}

A recent report by Zübeyde Nur Özkurt at Gazi University Hospital, Ankara Turkey in 2018, showed the link between capecitabine and secondary acute myeloid leukemia. It was a 39-year old female patient with bone metastatic breast cancer, Her2 / neu positive and ER / PR negative. The patient was treated with Trastuzumab, tamoxifen, leuprolide acetate, and ibandronic acid. 21 months later, switched to lapatinib (1250 $\mathrm{mg} /$ day) and capecitabine $\left(2000 \mathrm{mg} / \mathrm{m}^{2} /\right.$ day $)$, capecitabine ended in 9/2013 and patient was diagnosed with acute myeloid leukemia with the manifestations of CD13, CD33, CD34, CD117, MPO, CD64, and CD11b. The authors had found out a rearrangement of Clonal 46XX, (10; 11) (q22; q23); JAK2 gene mutation and no mutation of BCRABL, PML-RARA, AML1, CBFß-MYH11. 


\section{CONCLUSION}

Chemotherapy is one of the effective methods for cancer treatment and is recommended by prestigious cancer prevention associations and organizations in the world (NCCN, ASCO, ESMO) and becomes routine treatment when clinically indicated. Chemotherapy-related acute myeloid leukemia is rare and has been causeclassified in the WHO 2016 classification. Particularly, in clinical practice, we have encountered 3 cases in the Department of Chemotherapy - Center of Oncology-103 Military Hospital. These cases were treated with chemotherapeutic agents and 2 cases used granulocyte stimulating factor. One did not respond to primary acute myeloid leukemia regimen and had a short survival time (3 months) after diagnosis and 2 new cases were diagnosed and were undergoing treatment and follow up. In all 3 cases, before being diagnosed, there was no symptom, which is very difficult to diagnoses during the monitoring and treating time. So how to detect secondary AML early and find out an effective treatment method is still challenging for doctors. Therefore, before chemotherapy there is a need to explain clearly the benefits and undesirable effects for patients, as well as monitor and detect as soon as possible abnormal changes in blood counts of patients who are treated with risky chemotherapeutic agents or long-term usage of the chemotherapeutic drugs and do not misuse granulocyte stimulating factors.

Conflict of Interest: Authors have no conflicts of interest or financial ties to disclose.

Ethical approval: All procedures performed in the studies involving human participants were in accordance with the 1964 Helsinki declaration and it's later.

\section{REFERENCES}

1. Damodaran S et al (2012) "Acute myeloid leukemia secondary to oxaliplatin treatment for esophageal cancer" Clin Colorectal Cancer. 11:151-154

2. Godley LA, Larson RA (2008) "Therapyrelated myeloid leukemia" Semin Oncol; 35: 418-29

3. Morton LM et al (2018) "Association of Chemotherapy for Solid Tumors With Development of Therapy-Related Myelodysplastic Syndrome or Acute Myeloid Leukemia in the Modern Era" JAMA Oncol. doi: 10.1001

4. Zhang YC, Zhou YO, Yan B, et al (2015) "Secondary acute promyelocytic leukemia following chemotherapy for gastric cancer: A case report" World J Gastroenterol; 21: 44027

5. Zübeyde Nur Özkurt et al (2018) "Capecitabine Induced Therapy Related Acute Myeloblastic Leukemia with $t(10 ; 11)$ (q22;q23) in a Patient with Breast Cancer" Gazi University Faculty of Medicine, Department of Hematology, Ankara, Turkey 